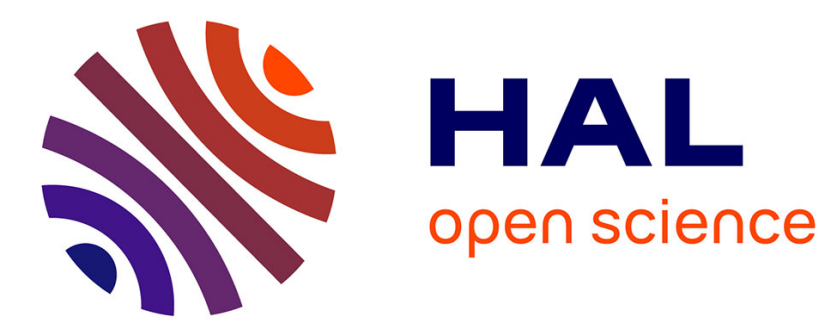

\title{
Stimulated phonon echoes in resonant powders
}

\author{
A. Billmann, Ch. Frénois, G. Guillot, A. Levelut
}

\section{To cite this version:}

A. Billmann, Ch. Frénois, G. Guillot, A. Levelut. Stimulated phonon echoes in resonant powders. Journal de Physique Lettres, 1978, 39 (21), pp.407-410. 10.1051/jphyslet:019780039021040700 jpa00231529

\section{HAL Id: jpa-00231529 \\ https://hal.science/jpa-00231529}

Submitted on 1 Jan 1978

HAL is a multi-disciplinary open access archive for the deposit and dissemination of scientific research documents, whether they are published or not. The documents may come from teaching and research institutions in France or abroad, or from public or private research centers.
L'archive ouverte pluridisciplinaire HAL, est destinée au dépôt et à la diffusion de documents scientifiques de niveau recherche, publiés ou non, émanant des établissements d'enseignement et de recherche français ou étrangers, des laboratoires publics ou privés. 


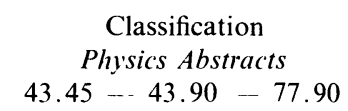

\title{
STIMULATED PHONON ECHOES IN RESONANT POWDERS
}

\author{
A. BILLMANN, Ch. FRÉNOIS, G. GUILLOT and A. LEVELUT \\ Laboratoire d'Ultrasons $\left({ }^{*}\right)$, Université Pierre-et-Marie-Curie, \\ Tour 13, 4, place Jussieu, 75230 Paris Cedex 05, France \\ (Reçu le 27 avril 1978, révisé le 12 septembre 1978, accepté le 15 septembre 1978)
}

\begin{abstract}
Résumé. - On présente diverses expériences sur l'écho de phonons à $T+\tau$ (ou écho stimulé) dans des poudres de quartz à la résonance mécanique. L'étude des dépendances angulaires et en puissances apporte de nouvelles informations sur son comportement. L'écho persiste même après tamisage de la poudre. La nature de l'état figé demeure inconnue.
\end{abstract}

\begin{abstract}
Experiments on stimulated phonon echoes in resonant quartz powders are reported. Angular dependence and power dependence studies give new information about their behaviour. Sieving the powder does not completely destroy the echo. The nature of the frozen state is not yet understood.
\end{abstract}

1. Introduction. - Phonon echoes in piezoelectric powders present very peculiar features when the particles of the powder are at the mechanical resonance, i.e. when their size is typically equal to one acoustical half-wavelength at the frequency of the experiment. The most striking result concerns the relaxation time $T_{1}$ of the stimulated echo. This echo is obtained when two electromagnetic pulses (at times 0 and $\tau$ ) create a frozen state which can reradiate an echo at time $T+\tau$ when it is excited by a third pulse (at time $T$ ). The time $T_{1}$ may be as long as months [1-3].

Melcher and Shiren (M.S.) [2] have tried to specify the nature of the frozen and therefore to explain its very long lifetime. They assume that the frozen state is obtained from the initial state by a rotation through an angle specific for every particle. The first pulse excites in all the particles an elastic dipolar moment and an associated (via piezoelectricity) electric dipolar moment. In the electric field of the second pulse this electric moment gives rise to a torque which rotates the particle with an angle depending on the amplitude of the two pulses, the delay $\tau$, the frequency, etc... The stored information are contained in the set of angles of all the particles. The third pulse re-excites

(*) Associated with the Centre National de la Recherche Scientifique. them and they radiate electromagnetic fields, whose resultant keeps the memory of the first two pulses having produced the rotations. The sum of all the elementary fields is zero except at the time $\tau$ after the stimulating pulse : it is the $T+\tau$ echo. It is quite clear that if the powder is shaken, the orientation is destroyed and the stimulated echo must disappear.

Recently a Russian group has published a result obtained on $\mathrm{KBrO}_{3}$ powder [4] which is very surprising in the context of the M. S. theory. After the information is recorded, if the powder is passed through a sieve, the stimulated echo persists with a loss of a factor 7 . These authors tentatively propose an explanation based on memorization by defects (dislocations).

In this paper we report on stimulated echo experiments done on quartz powder (sand). We first present a study of the angular dependence and of the power dependence of the echo. Our results show the existence of both isotropic and anisotropic behaviours; moreover we get some evidence of an erasing process. Secondly we confirm and precise the surprising result of the Russian group; in particular we show that the loss due to shaking or passing through a sieve depends actually on the reading pulse power (and therefore the number 7 has no physical meaning). Thirdly we give some results on partial additivity of the stored information which leads to a method for enhancing the echo. 
2. Apparatus. - For these experiments we have

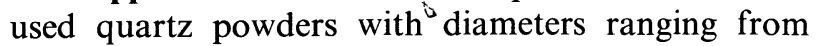
$63 \mu \mathrm{m}$ to $80 \mu \mathrm{m}$, obtained with the help of two adequate sieves. The samples were washed with a hydrofluoric acid solution.

The powders are maintained at room temperature and under a low pressure air atmosphere.

Most of the experiments are done with a vertical test-tube ( $4 \mathrm{~cm}$ height, $4 \mathrm{~mm}$ diameter) filled with $0.5 \mathrm{~cm}^{3}$ of powder (which contains about $10^{6}$ particles) and placed between the broad plates $(4 \mathrm{~cm} \times 2 \mathrm{~cm})$ of a plane capacitor. This system is not very efficient but the applied electric field is quite uniform and has a well defined orientation. The plates are fixed and we can rotate the test-tube around its vertical axis; we are able to measure the angle $\theta$ with an accuracy of $1^{\circ}$.

This system is part of a resonant electrical circuit, tuned at a frequency of $30 \mathrm{MHz}$.

3. Experimental results. - In all experiments, the echo is written in the powder by two coherent pulses of equal amplitudes separated by a time interval $\tau$. Because of the coherence, the echo amplitude increases up to a limit amplitude if the sequence of two pulses is repeated a great number of times. The writing sequences of two coherent pulses are applied until this limit is reached (about $5 \times 10^{3}$ sequences). For every experiment in the following we use virgin powder.

3.1 EXPERIMENT No 1. - The aim of the following experiment is to study the roles of the angle $\theta$ and of the pulse power when the reading electric field is at an angle $\theta$ from the writing field.

The two writing pulses have a rather strong power (equal for the two pulses). We call it $P_{\mathrm{W}}$; it corresponds to an applied electric field of about $2500 \mathrm{~V} . \mathrm{cm}^{-1}$. The direction of these fields is taken as reference $\theta=0$.

We have measured the amplitude $A(\theta)$ of the stimulated echo when the test-tube is rotated through an angle $\theta$ around its axis. The results which depend on the power $P_{\mathrm{R}}$ of the reading pulse are given in figure 1 .

Up to the level $P_{\mathrm{R}}=P_{\mathrm{W}}-15 \mathrm{~dB}$, the amplitude of the echo is quasi-independent of the angle $\theta$. Because of the axial symmetry of the experiment we may conclude that the observed isotropy in this (horizontal) plane where the reading electric field varies means that there is an isotropy in all the space (curve 1a).

The existence of an isotropic stimulated echo is another new experimental fact that the M. S. model could not predict.

When $P_{\mathrm{R}}$ is increased up to $P_{\mathrm{W}}$, the echo becomes more and more anisotropic (curves $1 b$ and $1 c$ ). It is stronger for $\theta=0$ (writing direction) than for $\theta=\pi / 2$; such a result has been observed by Cheeke et al. [5]. But our results are well fitted by :

$$
A(\theta)=\alpha \exp \left(a \cos ^{2} \theta\right) .
$$

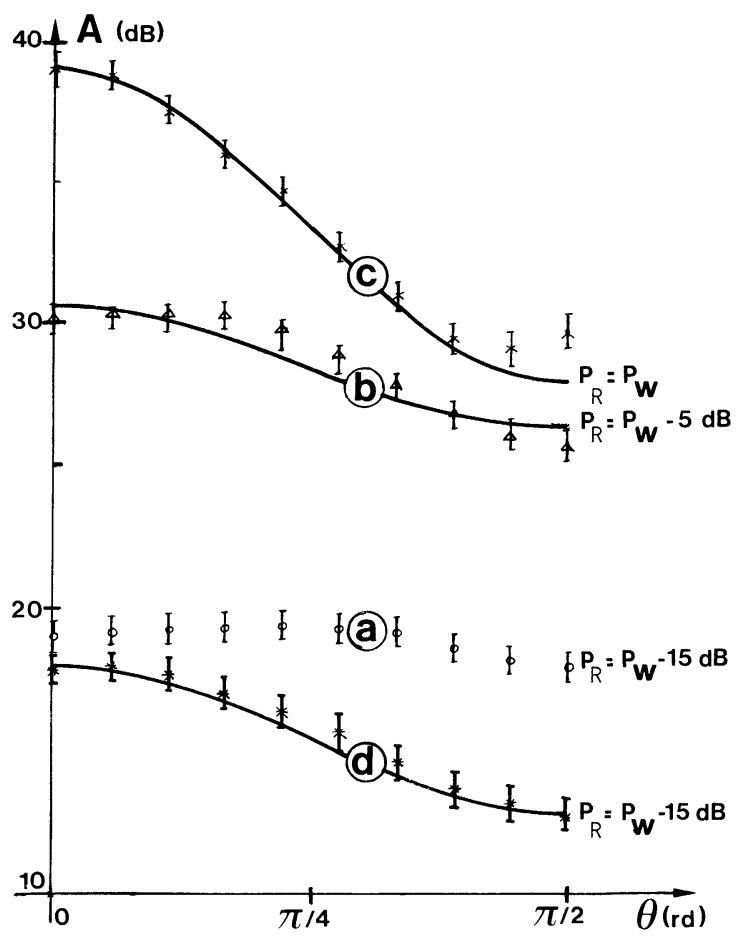

FIG. 1. - Stimulated echo amplitude as a function of the tube rotation angle $\theta$, for different reading powers $P_{\mathrm{R}}$ inferior or equal to the writing power $P_{\mathrm{w}}$. The echo was written at $\theta=0$. From $a$ to $c, P_{\mathrm{R}}$ increases from $P_{\mathrm{w}}-15 \mathrm{~dB}$ to $P_{\mathrm{w}}$, and the echo becomes more and more anisotropic. In curve $d$ if one comes back to $P_{\mathrm{R}}=P_{\mathrm{w}}-15 \mathrm{~dB}$, the echo is now more anisotropic than it was in curve $a$. Fits with $\alpha \exp \left(a \cos ^{2} \theta\right)$ are shown (continuous curves).

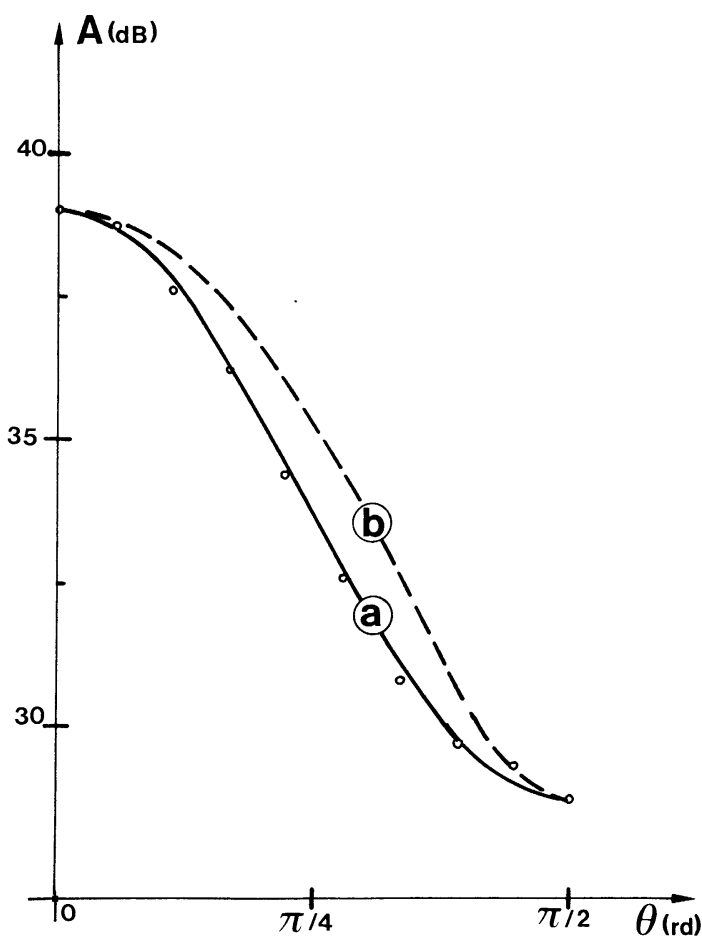

FIG. 2. - Stimulated echo amplitude read at $P_{\mathrm{R}}=P_{\mathrm{W}}$ (experimental points). Two fits are given :

$$
\begin{aligned}
& A(\theta)=\alpha \exp \left(a \cos ^{2} \theta\right) \quad(\text { curve } a) \\
& \left.A(\theta)=\alpha^{\prime} \cos ^{2} \theta+\beta^{\prime} \quad \text { (curve } b\right) \text {. }
\end{aligned}
$$


This is neither the result expected from M. S. theory and calculated in [6] nor that observed by Cheeke et al. [5]. In figure 2, our experimental results are compared with two laws :

$$
A(\theta)=\alpha \exp \left(a \cos ^{2} \theta\right)
$$

and

$$
A^{\prime}(\theta)=\alpha^{\prime} \cos ^{2} \theta+\beta^{\prime}
$$

as proposed by Cheeke et al. [5] (curves $2 a$ and $2 b$ ). Curve $2 a$ gives clearly the better fit.

If one comes back to the reading power

$$
P_{\mathrm{R}}=P_{\mathrm{W}}-15 \mathrm{~dB},
$$

the echo is no longer isotropic (curve $1 d$ ) : an anisotropic process has obviously erased the isotropic signal one could previously read at the same power (compare curve $1 a$ to curve $1 d$ ).

Finally, a pulse applied in the writing direction $(\theta=0)$ completely erases the echo for

$$
P>P_{\mathrm{w}}+6 \mathrm{~dB} \text {. }
$$

If such an operation is not done or if it is done at $\theta=\pi / 2$, the stimulated echo read at $\theta=0$ persists for days.

One must distinguish between two types of erasing processes. The total erasing can be achieved only if a pulse with a sufficient power is applied at $\theta=0$. In contrast partial erasing is only obtained with $P_{\mathrm{R}}<P_{\mathrm{W}}$ and it is more efficient for $\theta=\pi / 2$ than for $\theta=0$.

The influence of the power $P_{\mathrm{W}}$ has still to be systematically studied.

3.2 EXPERIMENT No 2. - Now we precise the effect of shaking or sieving the powder.

The echo is initially written with two high level pulses at $\theta=0$. Then :

i) It is read with a low leve pulse : it is isotropic. The powder is then vigorously shaken. The echo is still isotropic (an expected result) and the loss is typically between 1 and $3 \mathrm{~dB}$, depending on the way the powder is shaken; for instance, we may observe first a loss of $3 \mathrm{~dB}$ and after shaking again a loss of only $1 \mathrm{~dB}$ (i.e. with this second shaking the echo recovers a part of the apparent loss it showed after the first one). We believe that shaking introduces actually no real loss; the small loss observed appears probably because the particles are more or less tamped and the relaxation time $T_{2}$ is changed.

ii) When the echo is read with a high level pulse, it is anisotropic and shaking produces a noticeable loss. For example, we have observed for an anisotropy of $12 \mathrm{~dB}$ (difference between the maximum at 0 and the minimum at $\pi / 2$ ) that shaking makes the echo isotropic with a loss of $7 \mathrm{~dB}$ as compared to the maximum at $\theta=0$.

In order to check the efficiency of our shaking we pass the powder through the same sieve $(80 \mu \mathrm{m})$ which had been used to prepare it. The results are not changed; the losses are typically : $3 \mathrm{~dB}$ for a low reading level and $10 \mathrm{~dB}$ for a high level.

These experiments fully confirm a previous result [4] but in addition they show that the observed loss is strongly power dependent.

Here we examine the additivity of recorded information (experience No 3) and how we use it (experience No 4).

3.3 EXPERIMENT No 3. - We write successively two echoes at the same frequency, and with the same $\tau$ but along two discrete perpendicular directions (and not along intermediate directions). This experiment shows that stored signals with fields along different directions partly add. In figure 3 are reported :

- an echo written at $\theta=0$ and read at $P_{\mathrm{R}}=P_{\mathrm{W}}$, which fits quite well a law $A_{1}(\theta)=\alpha \exp \left(a \cos ^{2} \theta\right)$ (curve 3a);

- the same echo represented as if it were written at $\theta=\pi / 2$ and which should fit a law

$$
A_{2}(\theta)=\alpha \exp \left(a \sin ^{2} \theta\right)
$$

(curve $3 b$ );

- the sum of the amplitudes of the two echoes $B(\theta)=\alpha \exp \left(a \cos ^{2} \theta\right)+\alpha \exp \left(a \sin ^{2} \theta\right)$ (curve $\left.3 c\right)$;

- the experimental results which reproduce the shape of curve $c$ but with a lower amplitude indicating an only partial additive process (curve $3 d$ ).

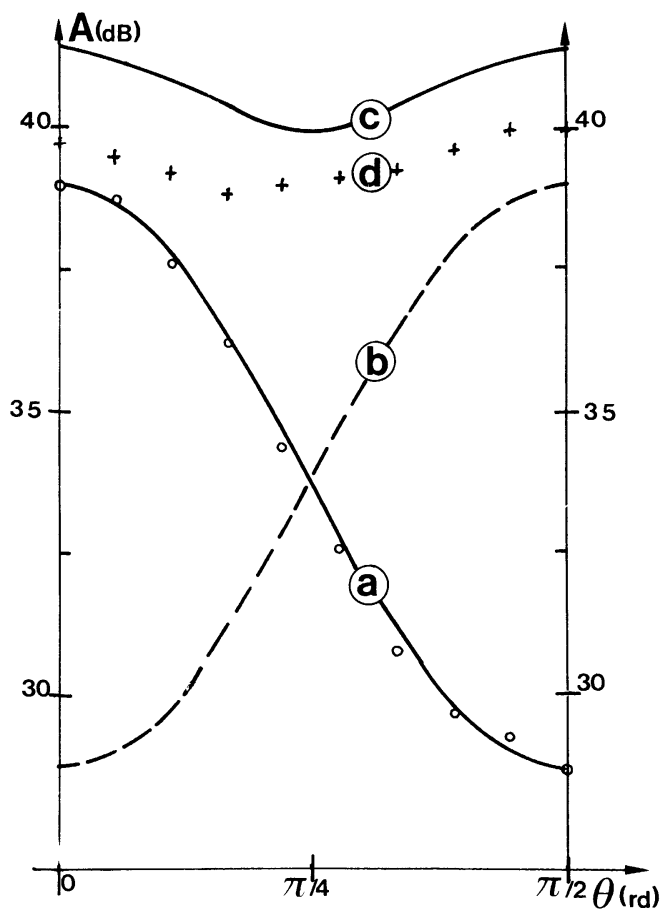

Fig. 3. - Information is stored at $\theta=0$ and read at $P_{\mathrm{R}}=P_{\mathrm{W}}$. Experimental points (open circles, the same as in Fig. 2) are well fitted by $A(\theta)=\alpha \exp \left(a \cos ^{2} \alpha\right.$ ) (curve $a$ ). A second information is stored with the same conditions at $\theta=\pi / 2$. If read independently at $P_{\mathrm{R}}=P_{\mathrm{w}}$, it would give $A(\theta)=\alpha \exp \left(a \sin ^{2} \theta\right)$ (curve $b$ ). Curve $c$ is the sum of the echo amplitudes given by curves $a$ and $b$. Reading after the double storage gives experimental points (crosses) which show the partial additivity of the amplitudes. 
3.4 EXPERIMENT No 4. - Here we have used two more efficient systems : a test-tube, containing along its axis a metallic rod-shaped electrode, put in a coil, and a cylindrical copper capacitor filled directly with powder. These two other systems are also part of a $30 \mathrm{MHz}$ resonant electrical circuit. In the present experiment we use the previous result (experiment No 3) to enhance the read echo by writing it in the system previously used (experiments No 1 to 3 ) when slowly turning the test-tube over an angle $\pi$ and simultaneously tapping it. Then the powder is transferred in the coil system; the stimulated echo appears at a time $\tau$ after the reading pulse. The powder is then transferred in the cylindrical copper capacitor; because this system is very efficient, the stimulated echo which is still observed is as strong as it was in the original system. This experiment proves unambiguously that the information follow every particle. Moreover these results are important for devices : the echo is enhanced by a continuous writing and it is not necessary to carry the apparatus with the powder.

4. Conclusion. - We have observed new features of the stimulated echo in quartz powder. The angular dependence of the echo amplitude is strongly dependent on the ratio of the reading to writing power : it is isotropic for low reading levels, and has a strong angular dependence as the reading power increases up to the writing power level. The memorization is due to an internal variable : this is demonstrated by the effect of shaking or sieving the powder which does not destroy the echo. But the nature of the internal variable is not really known. We have not obtained any evidence of the applicability of the M. S. theory : the persistence of an isotropic signal for low reading levels as well as the angular dependence observed for high reading levels are in conflict with the predictions of this theory.

Moreover, it seems that our results give a new interest in memory devices with phonon echoes : it is possible to keep information in a system insensitive to shocks or vibrations, movable into several parts and which does not need energy during the very long storage time.

Acknowledgments. - We thank J. D. N. Cheeke for communicating his results prior to publication.

\section{References}

[1] Kuindersma, P. I., Huizenga, S., Kommandeur, J. and Sawatsky, G. A., Phys. Rev. B 13 (1975) 496.

[2] Melcher, R. L. and Shiren, N. S., Phys. Rev. Lett. 36 (1976) 888.

[3] Popov, S. N., Krainik, N. N. and Smolenski, G. A., Sov. Phys. JETP 42 (1976) 494
[4] Berezov, V. M. and Romanov, V. S., Sov. Phys. JeTP Lett. 25 (1977) 151.

[5] Cheeke, J. D., Lakhani, A. A. and Ettinger, H., Solid State Commun. 25 (1978) 289.

[6] Ettinger, H., Lakhani, A. A. and Cheeke, J. D., to be published. 